\title{
Serratia odorifera Biogroup 1
}

National Cancer Institute

\section{Source}

National Cancer Institute. Serratia odorifera Biogroup 1. NCI Thesaurus. Code C124396.

A subspecies of Serratia odorifera that is ornithine decarboxylase positive and ferments raffinose and sucrose. 